\title{
New Information on the Ion-Identity Dependent Structure of Stern Layer Revealed by Sum Frequency Generation
}

\section{Vibrational Spectroscopy}

Kaitlin A. Lovering, Allan K. Bertram, and Keng C. Chou

Department of Chemistry, University of British Columbia, Vancouver, BC V6T 1Z1, Canada

Additional SFG Spectra of salt solutions.

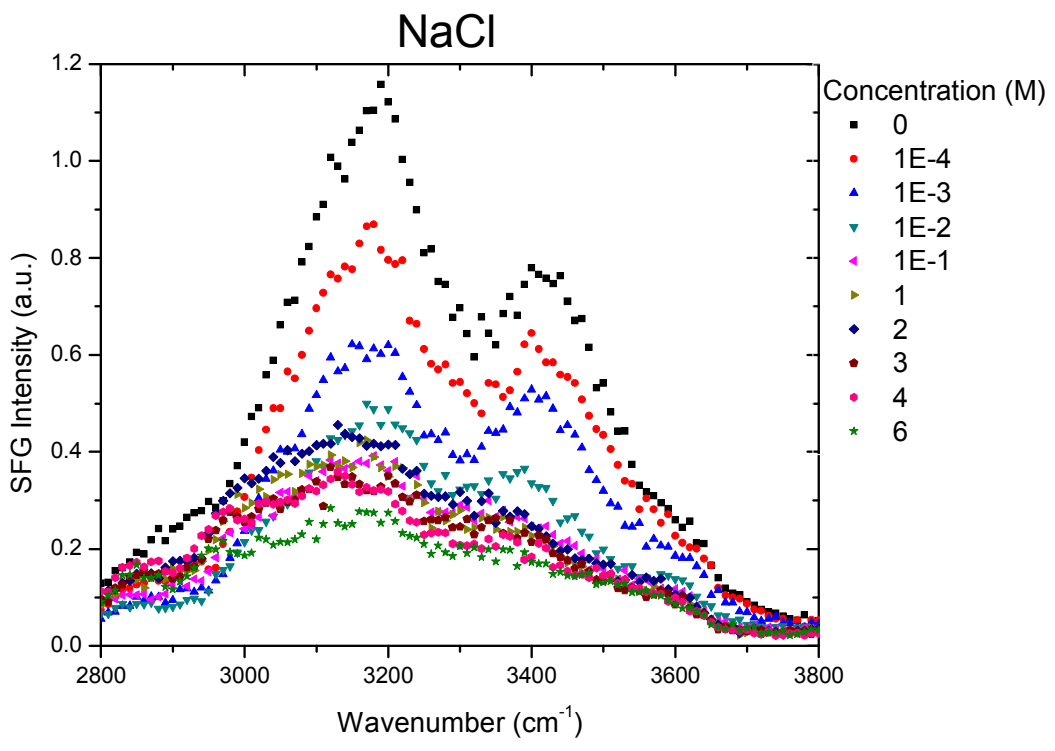

Figure S1. The spectra of $\mathrm{NaCl}$ solutions at various concentrations. 


\section{Supporting Information}

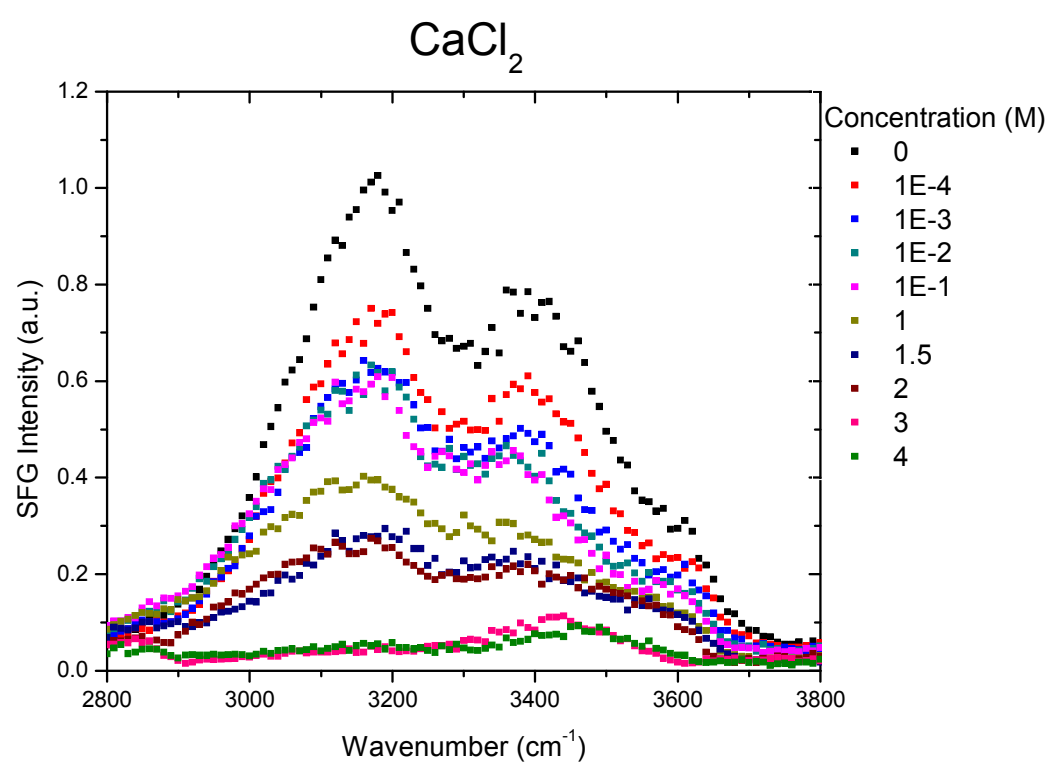

Figure S1. The spectra of $\mathrm{CaCl}_{2}$ solutions at various concentrations.

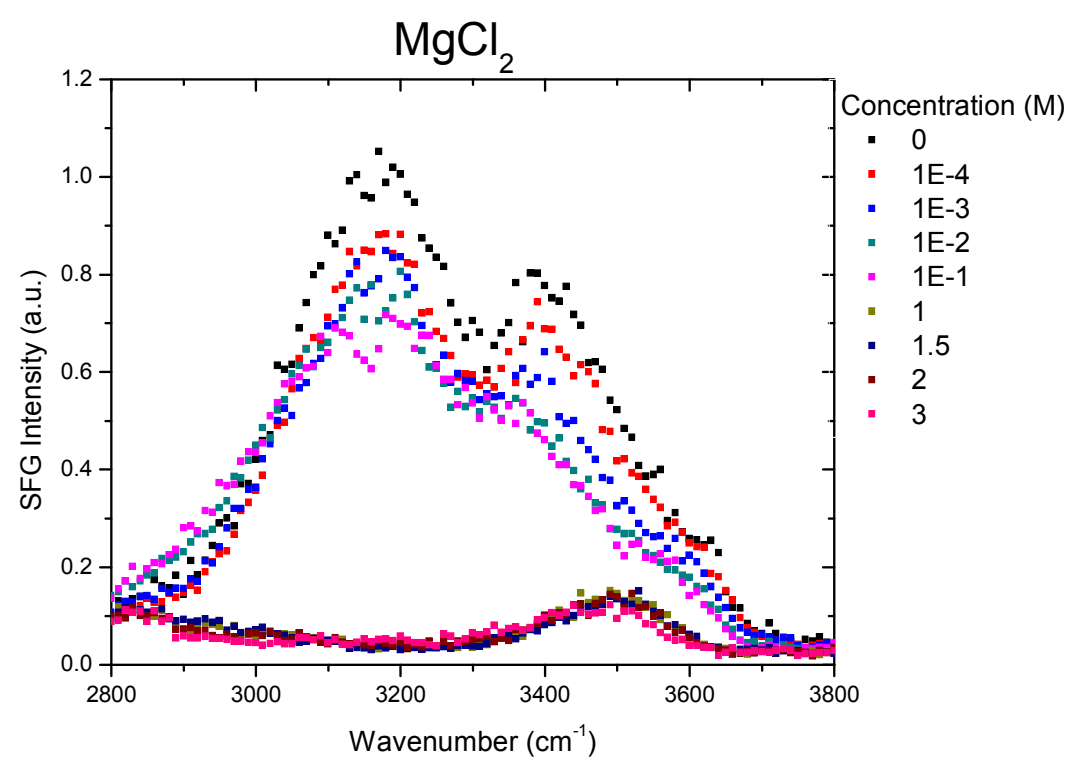

Figure S1. The spectra of $\mathrm{CaCl}_{2}$ solutions at various concentrations. 